ISSN No. $2454-1427$

CDE

August 2015

\title{
Optimal Value of a Patent in an Asymmetric Cournot Duopoly Market
}

\section{Uday Bhanu Sinha}

Email: uday@econdse.org

Department of Economics

Delhi School of Economics

\section{Working Paper No. 245}

http:/www.cdedse.org/working-paper-frameset.htm

\author{
CENTRE FOR DEVELOPMENT ECONOMICS \\ DELHI SCHOOL OF ECONOMICS \\ DELHI 110007
}




\title{
Optimal Value of a Patent in an Asymmetric Cournot Duopoly Market
}

\author{
Uday Bhanu Sinha \\ Delhi School of Economics
}

\section{Version: August 2015}

\begin{abstract}
We consider a mechanism for optimizing the value of a patent owned by an independent patent holder who is not a producer in the market. We consider two kinds of cost reducing innovations: "common innovation" and "new technology innovation" in a homogeneous good Cournot market with ex-ante asymmetric costs of production. We show that the value of the patent is maximized when the patent holder sells the patent to the efficient firm at a fixed payment who would further license the innovation to its rival. This patent sale dominates all other licensing mechanisms for both kinds of innovations.
\end{abstract}

Keywords: Patent sale; licensing; asymmetric firms; cost reducing innovation; auction; fixed fee; royalty, two part tariff.

JEL Classifications: D43; D44; D45; L13, O32, O33.

Address for Correspondence: Uday Bhanu Sinha, Department of Economics, Delhi School of Economics, University of Delhi, Delhi 110007, India. Email: uday@econdse.org 


\section{Introduction}

The literature on patent licensing has studied the optimal licensing strategy of a patent holder who could be an independent research laboratory which does not produce the good embedded with the patent (called outsider patentee) or an incumbent firm in the market (called insider patentee). The critical question is how does an independent patent holder who does not produce the good maximize the value of its patent? The literature on patent licensing is quite vast and is growing rapidly. The early literature was mainly concerned about the outsider patentee (Kamien and Tauman, 1986; Kamien et al., 1992; also see Kamien, 1992 for a survey). For the outsider patent holder the optimal licensing strategy is to auction a certain number of licenses in order to extract the maximum surplus from a cost reducing innovation (see Katz and Shapiro, 1985; Sen and Tauman, 2007). In particular, Kamien and Tauman (2002) found that an industry incumbent favours licensing by means of a royalty while an outsider patentee prefers to auction off a fixed number of licenses outright. ${ }^{1}$ Stamatopoulos and Tauman (2009) showed an interesting possibility that in an asymmetric Cournot duopoly market, the optimal licensing strategy for an outside patentee is to charge a fixed fee which is better than auction. On the other hand, Tauman and Weng (2012) considered selling of patent rights by an outside innovator, which may be a better option in some situations.

The main focus of the literature on outside patent licensing remains to be for the firms with symmetric cost of production prior to innovation in Cournot market and the amount of cost reduction is uniform across all firms if the innovation is used..$^{2}$ In this paper, we depart from this tradition and analyse the optimal licensing strategy of the outsider patentee when there are two potential licensees of the innovation, who differ in their pre-innovation costs and consider two types of innovations. In a 'common innovation' the cost of production of both firms would be

\footnotetext{
1 There exists a branch of licensing literature which focuses on a two-part tariff licensing contract in models with incomplete (asymmetric) information or uncertainty (see Gallini \& Wright, 1990; Macho-Stadler et al., 1991; Bousquet et al., 1998; Poddar \& Sinha, 2008 etc.). The optimality of a two-part tariff licensing contract under complete information is analysed by Fauli-Oller \& Sandonis (2002); Saracho (2002); Mukherjee (2007) and so on. In particular, Poddar and Sinha showed the optimality of two part tariff licensing contract in an asymmetric Cournot duopoly market. More interestingly, Lu and Poddar (2014) showed that a two-part tariff licensing contract is always optimal to the insider patentee in spatial models (both Hotelling and Salop) irrespective of the size of the innovation or any pre-innovation cost asymmetries.

${ }^{2}$ Poddar and Sinha (2010) was an exception to begin with.
} 
reduced by the same magnitude from their existing cost levels. The existing literature on licensing is entirely focused on this type of common innovation. We introduce a new dimension to this licensing literature by considering another type of innovation which we call 'new technology innovation' where the existing production technology has to be entirely replaced with the new technology. ${ }^{3}$

We consider a general mechanism for transferring the technology by an outside patent holder such as an R\&D Laboratory. We consider two types of options for transferring the technology to the market competitors: patent sale and direct licensing. Under the option of patent sale the outside innovator sells the patent rights to only one firm in the market, who then becomes the new owner of the technology. Under direct licensing the outside innovator retains its patent rights and licenses the technology to the market participants directly by using the standard licensing mode of fixed fee, royalty or auction. Thus, under the option of patent sale since the outside patent holder transfers the patent right to the party who buys the patent, the new owner of the patent can then decide whether to license that patent or not to its rivals and if so, then it decides on the terms of licensing contract. However, under direct licensing the firm holding the license to use the technology cannot further license it to another party. We show that the maximum value of a patent can be realized by selling the patent right at a fixed upfront payment to one firm and then that firm further licenses the technology to its rival using the optimal licensing contract. Though the patent sale can also be performed by an auction but we will show that in an asymmetric Cournot market, auction would be inferior to the direct sale of patent right to one of the firms. ${ }^{4}$ Interestingly, an outsider patentee would sell both kinds of cost reducing innovations at a fixed payment to the efficient firm. We also show that auction, fixed fee or royalty licensing would be inferior to the technology sale in the asymmetric Cournot market.

\footnotetext{
${ }^{3}$ The precise definitions are made clear in the next section.

${ }^{4}$ There is an alternative way of interpreting the problem at hand. Patent sale can also be thought of as a fixed fee exclusive licence to one of the firms with the possibility that it could further license the technology to any other party. Thus, apart from the licensing payments considered in the literature, the patentee can write a contract on whether the license holder can further license the technology to other rival in the same industry. In the existing theoretical literature, it is assumed (though implicit in most cases) that the license holder cannot license it further on its own. In case we allow for the possibility of licensing contract contingent on relicensing then that contract will also maximize the value of the patent. This requires that the outside patentee on its own does not further licenses the technology to other firms in the industry. Thus, this option may be equivalent to the patent sale in certain contexts.
} 
Our paper is very closely related to Tauman and Weng (2012). They also considered the selling of patent rights versus direct licensing by an outside innovator for symmetric cost firms and the buyer of the patent rights then licenses the technology to other firms in the industry. They focus on the incentive for innovation of an outside innovator and show that the innovation incentive is higher for the outside innovator when the patent right is sold than when it is licensed. Using linear demand they conclude that for large innovation patent sale strategy would be better than direct licensing for an industry with greater than four firms. On the contrary, we consider two potential licensees in an asymmetric duopoly case and show that even for smaller innovations the patent sale to one firm is better than the direct licensing. Also in our paper with asymmetric pre-innovation costs of firms, the auctioning of patent right to one firm is not the best strategy for the outside innovator.

This paper is also related to Stamatopoulos and Tauman (2009) which showed that in an asymmetric Cournot duopoly market for an outside patentee fixed fee is better than auction. In their paper the efficient firm would not use the technology but would shelve it; whereas the inefficient firm would use the technology and under certain parameter configuration it is the less efficient firm who will buy the license under fixed fee and the more efficient firm would not buy the innovation. However, in this paper we allow that cost reducing innovations are useful for both firms. We show that the option of patent sale with the possibility of further licensing helps the patent holder to extract maximum surplus as compared to any other mechanism in an asymmetric Cournot market for common as well as new technology innovations. Most importantly, we show that the efficient firm always gets the technology while it is not the case in Stamatopoulos and Tauman (2009).

The rest of the paper is organized as follows. Section 2 sets up the framework of our analysis. Section 3 analyses optimal technology transfer mechanism for a common innovation. Section 4 focuses on the new technology innovation. We conclude our paper in section 5. Some proofs are relegated to the Appendix. 


\section{The Framework}

Consider a market with two asymmetric firms: an efficient firm and an inefficient firm, producing a homogenous good. Firms are asymmetric in terms of their pre-innovation production costs. The efficient firm has a constant marginal cost of production $c_{1}$ and the inefficient firm has a constant marginal cost $c_{2}$ where $c_{1}<c_{2}$. Firms compete in quantities as Cournot duopolists. The inverse demand function is given by $p=a-Q$, where $p$ denotes price, $Q$ represents aggregate output in the market and $a$ is the positive demand intercept. We assume in the pre-innovation stage both firms are active in production, and this would imply the condition $\left(a-2 c_{2}+c_{1}\right)>0$ is satisfied. We assume that there is an outsider patentee who holds the patent for an innovation but cannot directly produce the product for the market. This innovation is cost reducing type, i.e., if the innovation is adopted by the incumbent firms in the market then it would reduce the existing costs of production of the firms. Given the ex-ante asymmetry of firms the nature of innovation can be of two types: 'common innovation' which reduces the cost of production for both firms by an equal magnitude from their existing levels of production costs and 'new technology innovation' where the existing technologies would have to be replaced completely and the new cost of production would be the same for both firms when the innovation is adopted. We assume that in case of common innovation the amount of cost reduction per unit of output is given by $\varepsilon(>0)$ as a result the marginal cost of production for the efficient firm becomes $c_{1}-\varepsilon$, and for the inefficient firm it is $c_{2}-\varepsilon$ if they use the innovation. ${ }^{5}$ For a meaningful story of licensing, both firms should have positive marginal costs of production even after adopting the common innovation. So we only need to assume that the size of innovation is such that $c_{1}-\varepsilon>0$. Thus, $c_{2}-\varepsilon>0$ naturally holds. We assume that the technology is non-drastic (See Tirole, 1988, p 391). This puts an upper bound on the magnitude of the the cost-reducing innovation which is given by assumption

Assumption 1. $0<\varepsilon<a-2 c_{2}+c_{1}$.

\footnotetext{
${ }^{5}$ As an example, think of a situation where two firms use two different types of technologies but they use one common device, which can be improved upon using the innovation. Under such circumstances, it is always possible for the innovator to reduce the costs of production of both the firms equally by using the common innovation. See Poddar and Sinha (2010) for a discussion on this.
} 
In case of new technology innovation we assume that the new technology leads to a marginal cost of production $\mathrm{c}$ such that $0<c<c_{1}<c_{2}$. So the difference in pre-innovation costs is wiped out post innovation and any firm that uses the new technology would have the lowest cost $\mathrm{c}$. Thus, the new technology leads to different amounts of cost reduction for the efficient firm and the inefficient firm. For the efficient firm the cost reduction would be $\delta_{1}=c_{1}-c$ and for the inefficient firm the cost reduction would be $\delta_{2}=c_{2}-c$. So, $\delta_{1}<\delta_{2}$. We assume that the new technology innovation is non-drastic..$^{6}$ Thus, we have

Assumption 2. $c_{2}<\frac{a+c}{2}$

We would analyse the optimal mechanism for transferring technology for an outside patentee for both types of innovations. First, we look at the ensuing competition when none of the firms receive the technology from the outside patentee and they compete in a Cournot duopoly with their existing technologies.

Given the marginal costs $c_{1}$ and $c_{2}$, respectively, the Nash equilibrium quantities for the efficient and the inefficient firms are:

$$
q_{1}=\frac{a-2 c_{1}+c_{2}}{3} \text { and } q_{2}=\frac{a-2 c_{2}+c_{1}}{3}
$$

Thus, the profits of the firms are

$$
\pi_{1}^{0}=\frac{\left(a-2 c_{1}+c_{2}\right)^{2}}{9} \text { and } \pi_{2}^{0}=\frac{\left(a-2 c_{2}+c_{1}\right)^{2}}{9}
$$

The outsider patentee has two options: (a) sell the patent to one firm; (b) license the patent directly. In option (a) the new owner of the patent can choose whether to license it further or not. In option (b) there is no scope for further licensing as the licensee does not own the patent right. For the sale of technology the patent holder can either hold an auction or make a direct sale offer by asking a price. In case of auction mechanism for sale the highest bidder would receive the technology by paying its bid price (first price sealed bid auction). In case of direct sale offer the

\footnotetext{
${ }^{6}$ The implications of drastic innovations are discussed at the end of section 4.
} 
patent holder approaches the two firms in a sequence. ${ }^{7}$ If the first firm accepts the offer the sale is executed. And if the offer is rejected by the first firm then the patent holder approaches the second firm. If none of them accepts then the technology remains unutilized with the outside patentee. For the option of licensing the technology, the outside patent holder can either licenses the technology to one firm or to two firms by setting royalty, fixed fee, or a combination of both or by holding an auction. Formally, in licensing through auction if the patentee wants to offer two licenses then it has to fix a minimum bid. In such a situation, the auction with minimum bid is equivalent to a fixed fee price setting by patentee and whosoever is willing would get the license by paying that fixed payment. So we will consider the non trivial version of the auction and in that case the number of license offer would be one. When the two licenses are offered by the patentee by fixing a fee, royalty or two part tariff then both firms simultaneously decide whether to accept or reject the license.

We consider the following three-stage game. In the first stage, the outside patentee decides on whether to sell the patent right of the innovation to one firm or to license the patent. In case of licensing offer the firms simultaneously decide whether to accept or not. In the second stage, if one firm buys the patent right then it decides whether to license the patent further to its rival and decides on the mode of payment. The rival firm decides whether to accept the offer or not. In case the patentee has chosen the licensing in the first stage of the game there is no scope for licensing in stage 2. Finally, in the third stage they compete in a homogenous goods market as Cournot duopolists. The fixed fee and auction payment are settled upfront whereas royalty payments are settled at the end of stage 3 after the production and sale of the outputs. Any firm would accept the technology if it is weakly better off than not accepting it.

\section{Common Innovation}

\section{1. Patent sale of common innovation}

The technology reduces the marginal cost of production by $\varepsilon$. In case of patent sale the new owner of the patent would have the opportunity to license it further in the second stage of the game. When the patent is sold in Stage 1 either in auction or in fixed fee the buyer $i$ would have a

\footnotetext{
${ }^{7}$ Note that the patent rights cannot be sold to more than one firm. Thus in sequential move the patent holder can utilise the threat of selling the patent right to the other firm later to maximise its revenue.
} 
marginal cost $c_{i}-\varepsilon$ for its own production. Then in the second stage if it wants to license the technology to the rival then the optimal licensing contract would depend on who has received the technology in the first stage. The following two lemmas would characterize the optimal licensing contract in the second stage of the game.

Lemma 1. If the buyer of the patent in the first stage is the efficient firm then it would license the technology to inefficient rival at a royalty rate $r^{*}=\varepsilon$ to maximize its payoff.

\section{Proof: See Appendix. ${ }^{8}$}

Given the third stage competition between the firms the efficient firm would receive the total payoff from the second stage game onwards after buying the patent at a fixed payment in the first stage

$$
\pi_{1}^{r^{*}=\varepsilon}=\frac{\left(a-2 c_{1}+c_{2}+2 \varepsilon\right)^{2}}{9}+\varepsilon\left(\frac{a-2 c_{2}+c_{1}-\varepsilon}{3}\right)
$$

Thus the maximum willingness to pay for the patent for the efficient firm would be the above payoff minus the amount it would receive when the inefficient firm receives the patent in the first stage. Note that if inefficient firm is the buyer of the patent in the first stage of the game it would optimally license it such that the efficient firm receives what it gets without the license. ${ }^{9}$ Thus, the last term below defines the profit of the efficient firm when the inefficient firm has the technology and the efficient firm does not have it. Hence, the efficient firm would be willing to pay for buying the patent,

$$
R_{1}=\frac{\left(a-2 c_{1}+c_{2}+2 \varepsilon\right)^{2}}{9}+\varepsilon\left(\frac{a-2 c_{2}+c_{1}-\varepsilon}{3}\right)-\frac{\left(a-2 c_{1}+c_{2}-\varepsilon\right)^{2}}{9}
$$

After simplification, $R_{1}=\varepsilon\left(a-c_{1}\right)$

Now we turn to the subgame when the inefficient firm buys the patent in the first stage of the patent sale game.

\footnotetext{
${ }^{8}$ Wang (1998) established that the optimal licensing contract in Cournot duopoly market with symmetric preinnovation costs would be only royalty equal to the amount of cost reduction.

${ }^{9}$ This case is analysed in details in Lemma 2 below.
} 
Lemma 2. If the buyer of the patent in the first stage is the inefficient firm then in the second stage it would license the technology to its efficient rival under either fixed fee, royalty, or a combination of both. The optimal licensing policy for the inefficient firm in stage 2 of the game is as given below. ${ }^{10}$

(a) for $_{2} \geq \frac{a+4 c_{1}+\varepsilon}{5}$, only a fixed-fee is charged and $f^{*}=\frac{4}{9} \varepsilon\left(a-2 c_{1}+c_{2}\right)$

(b) for $\frac{a+4 c_{1}+\varepsilon}{5}>c_{2}>\frac{a+4 c_{1}-\varepsilon}{5}$, a two-part tariff is charged.

(c) for $\frac{a+4 c_{1}-\varepsilon}{5} \geq c_{2}$, only a royalty is charged and $r^{*}=\varepsilon$.

\section{Proof: See Appendix.}

Given the licensing strategy of the inefficient firm the payoff to the inefficient firm from stage 2 onwards would be dependent on the structure of the second stage licensing fee.

Take the extreme case (i), when only fixed fee licensing is optimal i.e. when $c_{2} \geq \frac{a+4 c_{1}+\varepsilon}{5}$ then the fixed fee $f^{*}=\frac{4}{9} \varepsilon\left(a-2 c_{1}+c_{2}\right)$

Profit from own production plus fixed fee revenue is

$$
\frac{\left(a-2 c_{2}+c_{1}+\varepsilon\right)^{2}}{9}+\frac{4}{9} \varepsilon\left(a-2 c_{1}+c_{2}\right) \text {. }
$$

The willingness to pay for the patent for the inefficient firm is the above payoff minus what it receives in case the rival buys the patent. So,

$$
R_{2}=\frac{\left(a-2 c_{2}+c_{1}+\varepsilon\right)^{2}}{9}+\frac{4}{9} \varepsilon\left(a-2 c_{1}+c_{2}\right)-\frac{\left(a-2 c_{2}+c_{1}-\varepsilon\right)^{2}}{9}
$$

So $R_{2}=\frac{4}{9} \varepsilon\left(2 a-c_{1}-c_{2}\right)$

\footnotetext{
${ }^{10}$ The intuition for the results is duly explained in Poddar and Sinha (2010). In particular, the reason for fixed fee licensing arises due to large enough initial cost difference between the firms, and the inefficient firm would benefit by shifting production to the more efficient firm and then extracting the surplus through fixed fee licensing.
} 
Consider case (ii): $\frac{a+4 c_{1}+\varepsilon}{5}>c_{2}>\frac{a+4 c_{1}-\varepsilon}{5}$. In the proof of Lemma 2 given in the Appendix, we have derived the optimal values of $r^{*}=\frac{\left(a-5 c_{2}+4 c_{1}+\varepsilon\right)}{2}>0$ and $f^{*}=\frac{\left(a-2 c_{1}+c_{2}+\varepsilon-2 r^{*}\right)^{2}}{9}-\frac{\left(a-2 c_{1}+c_{2}-\varepsilon\right)^{2}}{9}$. Now the willingness to pay in the first stage of the game for the inefficient firm would be

$$
\begin{gathered}
R_{2}=\frac{\left(a-2 c_{2}+c_{1}+\varepsilon+r^{*}\right)^{2}}{9}+\frac{\left(a-2 c_{1}+c_{2}+\varepsilon-2 r^{*}\right)^{2}}{9}-\frac{\left(a-2 c_{1}+c_{2}-\varepsilon\right)^{2}}{9} \\
+r^{*}\left(\frac{a-2 c_{1}+c_{2}+\varepsilon-2 r^{*}}{3}\right)-\frac{\left(a-2 c_{2}+c_{1}-\varepsilon\right)^{2}}{9}
\end{gathered}
$$

Consider the other extreme case (iii) when only royalty licensing is optimal. Under royalty contract in the second stage licensing the willingness to pay in the first stage for the inefficient firm would be

$R_{2}=\frac{\left(a-2 c_{2}+c_{1}+2 \varepsilon\right)^{2}}{9}+\varepsilon\left(\frac{a-2 c_{1}+c_{2}-\varepsilon}{3}\right)-\frac{\left(a-2 c_{2}+c_{1}-\varepsilon\right)^{2}}{9}$

So, $R_{2}=\varepsilon\left(a-c_{2}\right)$

Note that the maximum willingness to pay for the patent in the first stage of patent sale for the inefficient firm is given by $R_{2}$ in equations (4), (5) and (6); and this is a continuously decreasing function of $c_{2}$ for the relevant range of $c_{2}>c_{1}$. Then the highest value of $R_{2}$ is attained when $c_{2}$ is reduced to approach $c_{1}$ in the limit. Thus, given the parameter configuration, $R_{1}>R_{2}$ for all $c_{2}>c_{1}$.

In the first stage of the game if patent sale is done through auction then the efficient firm would bid $R_{2}+\Delta$ where $\Delta>0$ but very small and would become the winner. Thus, in the first stage the outside patentee would expect to receive by auction $R_{2}+\Delta$, where $\Delta>0$ but very small. On the other hand, by setting price for the patent the outside patentee can make by direct sale offer is $R_{1}$ which the efficient firm would be willing to pay and $R_{1}>R_{2}+\Delta$. Thus, 
Lemma 3. In case the outsider patentee decides to sell the patent in the first stage of the game, then it does better by setting a fixed price for the patent than to auction it and the efficient firm buys the patent. The patentee receives the payoff $R_{1}=\varepsilon\left(a-c_{1}\right)$.

The intuition is that when there is an auction the two bidders would bid. The bidder with the higher valuation would just bid a tad above the willingness to pay of the rival as a result the payoff to the patentee is $R_{2}+\Delta$. Under direct patent sale the outside patentee can set the highest willingness to pay as the fixed price and the efficient firm would accept this offer.

\section{2. Patent Licensing of Common Innovation}

\section{2.1. Licensing to One Firm}

When one license is offered it must be done by a fixed fee. The licensee would receive the highest payoff when it can get the full advantage of the cost reduction in the competition with its rival. This larger payoff can be extracted by the outsider patentee with an upfront fixed payment. Any combination of fixed fee and royalty would reduce the amount of surplus subject to the participation constraint of the licensee. When only one license is offered then either both firms are willing to pay the fee but one of them gets the license or one of them agrees to pay and the other firm does not. To begin we assume that that both will be willing to pay for the license. When both firms are willing to get the license then if the efficient firm gets the license then its increment in payoff would be

$\frac{\left(a-2 c_{1}+2 \varepsilon+c_{2}\right)^{2}}{9}-\frac{\left(a-2 c_{1}+c_{2}-\varepsilon\right)^{2}}{9}$ and in case the inefficient firm gets the license then its increment in payoff would be $\frac{\left(a-2 c_{2}+2 \varepsilon+c_{1}\right)^{2}}{9}-\frac{\left(a-2 c_{2}+c_{1}-\varepsilon\right)^{2}}{9}$. Here if the firm rejects the offer then it believes that the other firm will accept it. So the maximum the patent holder can charge such that both firms are willing to get the license is the lower value of the two incremental profits, which happens for the inefficient firm and is given by $\frac{1}{3} \varepsilon\left(2 a-4 c_{2}+2 c_{1}+\varepsilon\right)$.

On the other hand, given the higher willingness to pay for the license by the efficient firm, the patentee can get a payoff by offering license to the efficient firm only. In that case, the efficient 
firm knows that if it does not accept the licensing offer the rival would not also get it. Hence, the maximum the patentee can extract as fixed fee from the efficient firm is

$$
\frac{\left(a-2 c_{1}+2 \varepsilon+c_{2}\right)^{2}}{9}-\frac{\left(a-2 c_{1}+c_{2}\right)^{2}}{9}=\frac{4 \varepsilon\left(a-2 c_{1}+c_{2}+\varepsilon\right)}{9} \text {. }
$$

However, depending on the parameter configuration one of them would be higher and thus, we can write that the patentee can get by offering only one license

$L^{1}(f)=\operatorname{Max} .\left\{\frac{1}{3} \varepsilon\left(2 a-4 c_{2}+2 c_{1}+\varepsilon\right), \frac{4 \varepsilon\left(a-2 c_{1}+c_{2}+\varepsilon\right)}{9}\right\}$

It also follows that auctioning one license would lead to a situation where a firm will bid slightly higher than what the rival would like to pay when one license is offered. Hence the auction would generate weakly lower payoff than $L^{1}(f)$ given in (7).

\section{2.2. Licensing to Two Firms}

We now consider the other option of offering two licenses directly to two firms at a uniform two part tariff $(f, r)$. Note that only fixed fee or only royalty are the two polar cases of this general uniform two part tariff.

Lemma 4. In case of licensing of common innovation to two firms the outside patentee would offer

(i) When $2 a \geq 13 c_{2}-11 c_{1}+6 \varepsilon$ then only fixed fee is charged and the patentee's payoff is

$L^{2}(f)=2\left[\frac{4}{9} \varepsilon\left(a-2 c_{2}+c_{1}\right)\right]$.

(ii) When $13 c_{2}-11 c_{1}+6 \varepsilon>2 a>13 c_{2}-11 c_{1}-6 \varepsilon$, the optimal licensing is a two part tariff and the patentee's payoff is

$$
L^{2}\left(f^{*}, r^{*}\right)=\frac{4 a^{2}+121 c_{1}^{2}+169 c_{2}^{2}+36 \varepsilon^{2}+168 a \varepsilon+44 a c_{1}-52 a c_{2}+60 \varepsilon c_{1}-228 \varepsilon c_{2}-286 c_{1} c_{2}}{216} .
$$

(iii) When $13 c_{2}-11 c_{1}-6 \varepsilon \leq 2 a$ then the patentee charges a uniform royalty $r^{*}=\varepsilon$ and thus the total payoff to the patentee would be $L^{2}(r)=\varepsilon\left[\frac{2 a-c_{1}-c_{2}}{3}\right]$.

Proof: See Appendix 
Since our purpose is to find the optimal value of a patent we are not comparing the payoffs of the outside patentee for one or two licenses to establish the optimal licensing contract in order to avoid additional algebra. Instead we would compare them directly with the payoff from the patent sale to establish our result.

By comparing the payoffs from the patent sale and patent licensing to one or two firms the next proposition completely characterizes the optimal mechanism for maximizing the value of the patent for the outsider patentee in an asymmetric Cournot duopoly market for a common innovation.

Proposition 1. The patent sale is strictly better than patent licensing directly to the firms for common innovation in asymmetric Cournot duopoly market. The outside patentee would sell the technology to the efficient firm and then the efficient firm further licenses the technology to its inefficient rival at a royalty rate $r^{*}=\varepsilon$ and thus, the outside patentee receives $R_{1}=\varepsilon\left(a-c_{1}\right)$.

Proof: See Appendix.

This result is very interesting as the only way to maximize the value of a patent for the outsider patentee is to sale the patent right to the efficient incumbent firm than directly licensing it to the asymmetric firms in a Cournot market. This proposition shows that the analysis of Wang and Yang (2004) by allowing auction fixed fee and royalty does not provide the best mechanism for maximizing the value of the patent for the outside patent holder.

\section{New Technology Innovation}

\section{1. Patent sale of new technology}

We proceed to find the optimal value of the patent for the outsider patentee in the same manner as we have done for the common innovation in the previous section. Recall that in case of new technology innovation the marginal cost of production $\mathrm{c}$ is such that $0<c<c_{1}<c_{2}$. 
Now suppose the outsider patentee sells the patent either by setting a price or in auction. In the next stage the buyer of the technology can choose to license it to its rival. The following lemma characterizes the optimal licensing strategy for the technology buyer to its rival.

Lemma 5. For a new technology innovation, after buying the technology in the first stage of the game, the technology buyer licenses the technology to its rival at a royalty equal to the amount of cost saving of its rival.

Proof: See Appendix.

First note that it is always optimal to license the new technology innovation after buying it. Interestingly, this optimality of the licensing contract is independent of the identity of firm $i$ whether efficient or inefficient to begin with. Thus, whoever buys the new technology innovation in the first stage of the game would license the technology in the second stage by using the royalty only. The amount of royalty is equal to the amount of cost reduction of the rival.

Thus, in the second stage when the efficient firm is the buyer of the technology then it would license to the inefficient firm at a royalty rate $\mathrm{r}=\delta_{2}=c_{2}-c$ and collect the royalty revenue depending on the output produced by the inefficient firm, which is always positive given the assumption of the non-drastic technology (Assumption 2).

When the new technology is sold to the efficient firm either in auction or in fixed fee the total payoff to the efficient firm would be

$$
\frac{\left(a-2 c+c_{2}\right)^{2}}{9}+\left(c_{2}-c\right) \frac{\left(a-2 c_{2}+c\right)}{3}
$$

On the other hand, if the inefficient firm buys the patent then it would also license the new technology to the efficient rival firm by asking for a royalty $\mathrm{r}=\delta_{1}=c_{1}-c$. Therefore, it would receive the payoff

$$
\frac{\left(a-2 c+c_{1}\right)^{2}}{9}+\left(c_{1}-c\right) \frac{\left(a-2 c_{1}+c\right)}{3} \text {. }
$$

Note that in the second stage, whoever is not able to get the technology in the first stage of technology sale would be licensed in the second stage at a royalty such that their effective marginal costs remain the same and they are actually competing with the technology buyer of the first stage whose marginal cost would be c. Thus, if a firm fails to buy the technology then given that the other firm would buy it, the payoffs to the efficient firm and the inefficient firm would be 


$$
\pi_{1}^{0}=\frac{\left(a-2 c_{1}+c\right)^{2}}{9} \text { and } \pi_{2}^{0}=\frac{\left(a-2 c_{2}+c\right)^{2}}{9}
$$

Thus, the efficient firm would be willing to pay for buying the patent in the first stage of the game

$$
T_{1}=\frac{\left(a-2 c+c_{2}\right)^{2}}{9}+\left(c_{2}-c\right) \frac{\left(a-2 c_{2}+c\right)}{3}-\frac{\left(a-2 c_{1}+c\right)^{2}}{9}
$$

Similarly, the inefficient firm would be willing to pay for buying the patent

$$
T_{2}=\frac{\left(a-2 c+c_{1}\right)^{2}}{9}+\left(c_{1}-c\right) \frac{\left(a-2 c_{1}+c\right)}{3}-\frac{\left(a-2 c_{2}+c\right)^{2}}{9}
$$

After simplification, by comparing $T_{1}$ and $T_{2}$ we find that $T_{1}>T_{2}$ iff $\frac{1}{9}\left(c_{2}-c_{1}\right)(a+c-$ $\left.c_{1}-c_{2}\right)>0$. This condition holds under Assumption 2 and given $c_{2}>c_{1}$.

Thus, in case of patent sale for a new technology innovation the outside patentee would sell the patent to the efficient firm who would further license the technology to the inefficient rival.

Again the similar argument holds that in the first stage the auction would be strictly inferior to direct sale at a fixed price since $T_{1}>T_{2}$. Thus, we have

Lemma 6. For the new technology innovation when the patent is sold by the outside patentee then it directly sells the technology to the efficient firm at a fixed price in the first stage of the game and the efficient firm in the second stage further licenses the technology to the inefficient firm at a royalty $\delta_{2}=c_{2}-c$. The outside patentee receives by selling the patent right $T_{1}=\frac{\left(a-2 c+c_{2}\right)^{2}}{9}$ $+\left(c_{2}-c\right) \frac{\left(a-2 c_{2}+c\right)}{3}-\frac{\left(a-2 c_{1}+c\right)^{2}}{9}$.

\section{2. Patent Licensing of New Technology}

\section{2. 1. Licensing to One Firm}


When one license is offered then it is standard that only fixed fee is charged. Suppose the fee is such that both are willing to accept the license. Then each firm knows that if it does not accept the licensing contract the technology would go to the other firm. Thus, the efficient firm is willing to accept the license provided that the fee is not more than $\left(\frac{\left(a-2 c+c_{2}\right)^{2}}{9}-\frac{\left(a-2 c_{1}+c\right)^{2}}{9}\right)$

The inefficient firm is willing to pay $\left(\frac{\left(a-2 c+c_{1}\right)^{2}}{9}-\frac{\left(a-2 c_{2}+c\right)^{2}}{9}\right)$

In order to keep the offer acceptable to both the patentee would have to charge

Min. $\left\{\frac{\left(a-2 c+c_{2}\right)^{2}}{9}-\frac{\left(a-2 c_{1}+c\right)^{2}}{9}, \frac{\left(a-2 c+c_{1}\right)^{2}}{9}-\frac{\left(a-2 c_{2}+c\right)^{2}}{9}\right\}$

On the other hand, if the offer of one license at a fee is such that it is acceptable to one firm only then the patentee offers the license to the inefficient firm only at a fixed fee which is given by ${ }^{11}$

$$
\begin{aligned}
& \mathrm{N}^{1}(\mathrm{~F})=\left(\frac{\left(a-2 c+c_{1}\right)^{2}}{9}-\frac{\left(a-2 c_{2}+c_{1}\right)^{2}}{9}\right) \\
& =\frac{2\left(c_{2}-c\right)\left(2 a-2 c_{2}+2 c_{1}-2 c\right)}{9}
\end{aligned}
$$

It is also clear that if one license is offered under auction then the maximum the outside patentee will get is the minimum payoff in (10) plus a small amount close to zero. However, the payoffs from patent sale would dominate each of the payoffs given in (10). Hence, the payoff under auction will also be dominated by the payoff from patent sale to the efficient firm (see the proof of proposition 2 in Appendix).

\section{2. 2. Licensing to Two Firms}

We consider the general licensing scheme involving a uniform two part tariff as a combination of a fixed fee and a royalty $(f, r)$ to both firms. We impose the natural restrictions that $f \geq 0$ and $r \leq \delta_{1}$. The following lemma characterizes the optimal licensing contract in case of two licenses.

\footnotetext{
${ }^{11}$ In a similar situation of one license to the efficient firm would yield a payoff to the patentee $\frac{2\left(c_{1}-c\right)\left(2 a-2 c_{1}+2 c_{2}-2 c\right)}{9}$, which is less than the payoff it gets from licensing to the inefficient firm given by (11).
} 
Lemma 7. In case of licensing of new technology innovation to two firms the outside patentee would offer the licensing contract

(i) When $c<c_{1}<\frac{a+3 c}{4}$, only fixed fee and the patentee's payoff is $N^{2}(f)=\frac{8}{9}\left(a-c_{1}\right)\left(c_{1}-c\right)$,

(ii) When $\frac{a+3 c}{4}<c_{1}<\frac{a+c}{2}$, the two part tariff and the patentee's payoff is $N^{2}(f, r)=\frac{(a-c-r *)^{2}}{9}-$ $\frac{\left(a-2 c_{1}+c+r *\right)^{2}}{9}+2 r *\left(\frac{(a-c-r *)}{3}\right)$, where $r *=\frac{4 c_{1}-3 c-a}{6}$.

Proof: See Appendix.

Thus, by comparing the payoffs from patent sale and patent licensing for the new technology innovation, we have our next proposition

Proposition 2. In case of new technology innovation the outside patentee chooses to sell the patent directly to the efficient firm at a fixed price and then the efficient firm licenses the technology to the inefficient rival at a royalty $\delta_{2}=c_{2}-c$. And the payoff to the outside patentee is $T_{1}=\frac{\left(a-2 c+c_{2}\right)^{2}}{9}+\left(c_{2}-c\right) \frac{\left(a-2 c_{2}+c\right)}{3}-\frac{\left(a-2 c_{1}+c\right)^{2}}{9}$.

Proof: See Appendix.

Thus, the option of licensing whether to one or two firms directly by the outside patentee is inferior to the sale of patent right to the efficient firm who subsequently licenses to the inefficient firm and thereby the outside patentee receives $T_{1}$. This result is in sharp contrast to Stamatopolous and Tauman (2009) where fixed fee though optimal for some parameter ranges in their model but the inefficient firm receives the technology by paying a higher fixed fee than the efficient rival who does not accept the technology under the fixed fee. Their result depends on the fact that the efficient firm shelves the technology in case it manages to get the technology. However, in our model the technology is useful for both firms and it is never shelved. Interestingly, the efficient firm always gets the technology, which is not the case in Stamatopoulos and Tauman (2009). Moreover, the efficient firm further licenses the technology to the inefficient rival.

Thus, we find that in order to maximise the value of the patent the outside patentee must sell the patent to the efficient firm by charging a fixed price upfront. The efficient firm 
subsequently licenses the innovation to its inefficient rival at a royalty fee. This is surprising as two different innovations apparently confer different cost advantages to two different firms who differ in their cost efficiencies before adopting the innovation. What is also interesting that both innovations would be sold at fixed prices but not under auction in the asymmetric duopoly case. Thus, contrary to the symmetric duopoly case where auction turns out to be the dominant mechanism for selling the technology for an outsider patentee (Tauman and Weng (2012)); we find that patent sale at a fixed price is the optimal strategy for the outsider patentee in an asymmetric Cournot duopoly market.

Before we conclude, let us discuss the implications of drastic innovation in the context of our paper. Note that the 'drastic' innovation entails that a firm with the drastic innovation receives the monopoly payoff in the market and the other firms receive zero profits. In case of common innovation, the optimal strategy for the outside innovator would be to transfer the drastic innovation to the efficient firm who would generate higher monopoly profit than the inefficient firm. The outside innovator can extract the entire monopoly profit either through a patent sale or by direct licensing to the efficient firm. The efficient firm would never license the drastic innovation to its rival. However, in case of new technology innovation, the drastic innovation would lead to the same amount of monopoly profit for both efficient and inefficient firms. So the outside innovator can extract the entire monopoly profit by offering the technology to one of the firms either by selling the patent or by direct licensing. The receiver of the technology would not further license the technology to its rival since the technology is drastic.

\section{Concluding Remarks}

The existing literature on patent licensing in the context of homogenous product Cournot oligopoly has mainly considered symmetric cost of production for the firms prior to innovation. We analyse the optimal licensing strategy of an independent patent holder (outside patentee) when it faces an asymmetric Cournot duopoly market. Though the standard optimal licensing strategy always involves either auction, fixed fee or royalty licensing for the case of symmetric cost Cournot oligopoly, it is never optimal in the asymmetric Cournot duopoly case. We have considered two types of cost reducing innovation: common innovation and new technology 
innovation. We have found that for both innovations it is optimal for the outside innovator to directly sell the patent right to the efficient firm at a fixed price who then further licenses the innovation to its less efficient rival. Thus, the paper brings into focus the significance of asymmetric pre-innovation costs in determining the optimal value of a patent in a Cournot duopoly market. The paper also demonstrates that much of the literature which differentiates between insider and outsider patentee would loose its relevance in general context where the patent sale to an insider firm is considered and after that the new patent owner can do what an insider patent holder would optimally do. Given the importance of this result it is indeed important to establish the robustness of this finding in a general Cournot oligopoly context. In view of our finding further research is needed in this area.

Once we have the above results in a Cournot duopoly case with linear demand, there are two natural questions that can be raised regarding the generalization. The first one relates to the general demand function. The main result of the paper is that the efficient firm gets the innovation under patent sale, and then licenses the technology to its rival. One would expect that this result would hold even for a class of demand functions which are close to linear in terms of curvature provided the other standard assumptions on the existence and uniqueness of Cournot equilibrium are maintained. The force of Cournot rivalry and the advantage of receiving the technology for the efficient firm would remain even in a general demand setup.

The second question is related to more number of firms in the product market than just two considered in the paper. Though, the model is analysed in a Cournot duopoly structure but our conjecture is that the basic finding of patent sale to one firm which then licenses the technology to other rivals in the market would hold even for a general oligopoly with asymmetric costs in some cases. An important caveat is that depending on cost asymmetry between the firms, the licensing by an insider might involve only a subset of firms and other strategic motives like inducing exit for some firms would also play a role. Thus, a straightforward generalization like the symmetric cost case would not be possible. 


\section{Appendix}

\section{Proof of Lemma 1:}

Consider that the efficient firm decides to license the innovation by offering a two part tariff contract $(f, r)$, where $f$ is the fixed-fee charged upfront and $r$ is the royalty rate per unit of output produced by the licensee. We assume both $f, r \geq 0$ and $r \leq \varepsilon$.

By accepting the licensing contract $(f, r)$, the inefficient firm receives $\frac{\left(a-2 c_{2}+c_{1}+\varepsilon-2 r\right)^{2}}{9}-f$.

In case the inefficient firm does not accept the licensing contract, it receives a payoff $\frac{\left(a-2 c_{2}+c_{1}-\varepsilon\right)^{2}}{9}$.

Thus, for a given $r$, the inefficient firm would accept the licensing contract if the fixed-fee is not greater than $f=\frac{\left(a-2 c_{1}+c_{2}+\varepsilon-2 r\right)^{2}}{9}-\frac{\left(a-2 c_{1}+c_{2}-\varepsilon\right)^{2}}{9}$.

Hence, the efficient firm can at the most charge this $f$ as the fixed-fee.

The efficient firm's payoff under this licensing contract would be its own profit in the product market due to competition plus the fixed-fee it charges and the royalty revenue it receives.

Thus, the efficient firm's total payoff is

$$
\begin{aligned}
\pi_{1}^{f+r}= & \frac{\left(a-2 c_{1}+c_{2}+\varepsilon+r\right)^{2}}{9}+\frac{\left(a-2 c_{2}+c_{1}+\varepsilon-2 r\right)^{2}}{9}-\frac{\left(a-2 c_{2}+c_{1}-\varepsilon\right)^{2}}{9} \\
& +r\left(\frac{a-2 c_{2}+c_{1}+\varepsilon-2 r}{3}\right) .
\end{aligned}
$$

This payoff is a concave function of $\mathrm{r}$ and the unconstrained maximisation with respect to

$r$ of the above payoff function yields $r=\frac{\left(a-5 c_{1}+4 c_{2}+\varepsilon\right)}{2}$. It is easy to check that due to Assumption 1, this value of $\mathrm{r}$ is greater than $\varepsilon$. Hence the optimal licensing would be at $r^{*}=\varepsilon$ and the fixed fee component would be zero.

\section{Proof of Lemma 2}

To prove this we just follow the proof of Proposition 1 in Poddar and Sinha (2010). 
Consider that the inefficient firm decides to license the innovation by offering a two part tariff contract $(f, r)$, where $f, r \geq 0$ and $r \leq \varepsilon$.

By accepting the licensing contract $(f, r)$ the efficient firm receives $\frac{\left(a-2 c_{1}+c_{2}+\varepsilon-2 r\right)^{2}}{9}-f$

In case the efficient firm does not accept the licensing contract, it receives a payoff $\frac{\left(a-2 c_{1}+c_{2}-\varepsilon\right)^{2}}{9}$.

Thus, for a given $r$, the efficient firm would accept the licensing contract if the fixed-fee is not greater than $f=\frac{\left(a-2 c_{1}+c_{2}+\varepsilon-2 r\right)^{2}}{9}-\frac{\left(a-2 c_{1}+c_{2}-\varepsilon\right)^{2}}{9}$.

Hence, the inefficient firm can at the most charge this $f$ as the fixed-fee.

The inefficient firm's payoff under this licensing contract would be its own profit in the product market due to competition plus the fixed-fee it charges and the royalty revenue it receives.

Thus, the inefficient firm's total payoff is

$$
\begin{aligned}
\pi_{2}^{f+r}= & \frac{\left(a-2 c_{2}+c_{1}+\varepsilon+r\right)^{2}}{9}+\frac{\left(a-2 c_{1}+c_{2}+\varepsilon-2 r\right)^{2}}{9}-\frac{\left(a-2 c_{1}+c_{2}-\varepsilon\right)^{2}}{9} \\
& +r\left(\frac{a-2 c_{1}+c_{2}+\varepsilon-2 r}{3}\right) .
\end{aligned}
$$

The unconstrained maximisation with respect to $r$ of the above payoff function yields $r=\frac{\left(a-5 c_{2}+4 c_{1}+\varepsilon\right)}{2}$.

Now depending on the parameter configurations we have the following three distinct possibilities. These possibilities arise due to the constraints $r \geq 0$ and $r \leq \varepsilon$.

Case (i): $c_{2} \geq \frac{a+4 c_{1}+\varepsilon}{5}$.

Then, we get $r \leq 0$ from (A3). Now given the natural restriction on $r \geq 0$, we argue that the optimal $r^{*}=0$ and the patentee would charge a fixed-fee only. Thus, the optimal amount of fixedfee is $f^{*}=\frac{\left(a-2 c_{1}+c_{2}+\varepsilon\right)^{2}}{9}-\frac{\left(a-2 c_{1}+c_{2}-\varepsilon\right)^{2}}{9}=\frac{4}{9} \varepsilon\left(a-2 c_{1}+c_{2}\right)$, and it is positive. 
Case (ii): $\frac{a+4 c_{1}+\varepsilon}{5}>c_{2}>\frac{a+4 c_{1}-\varepsilon}{5}$.

In this case the optimal royalty would be $r^{*}=\frac{\left(a-5 c_{2}+4 c_{1}+\varepsilon\right)}{2}>0$ and this $r *<\varepsilon$ as well. Therefore, in this case there would be a fixed-fee also. The fixed fee would be $f^{*}=\frac{\left(a-2 c_{1}+c_{2}+\varepsilon-2 r^{*}\right)^{2}}{9}-\frac{\left(a-2 c_{1}+c_{2}-\varepsilon\right)^{2}}{9}$, where $\mathrm{r}^{*}$ is given by (A3). Thus, we have a twopart tariff licensing scheme.

Case (iii): $\frac{a+4 c_{1}-\varepsilon}{5} \geq c_{2}$.

Then we get $r \geq \varepsilon$. Given the restriction that $r \leq \varepsilon$, we have the optimal $r^{*}=\varepsilon$. Hence, it is clear from the expression of the fixed-fee that $f^{*}=0$.

\section{Proof of Lemma 4}

First note that any offer of uniform two part tariff if accepted by the inefficient firm would also be accepted by the efficient firm. This is because given any $r$, the efficient firm would generate more surplus than the inefficient firm when two licenses are offered. Under the two part tariff contract the amount of fixed fee that can be charged given the royalty is such that the participation constraint of the inefficient firm is satisfied. Thus,

$$
f=\frac{\left(a-2 c_{2}+c_{1}+\varepsilon-r\right)^{2}}{3}-\frac{\left(a-2 c_{2}+c_{1}-\varepsilon+r\right)^{2}}{3}
$$

As a result of the two part tariff and the Cournot market competition thereafter, the outside patentee's payoff would be $2 f+r\left(q_{1}(f, r)+q_{2}(f, r)\right)$. Thus.

$$
\begin{aligned}
& L^{2}(f, r)=2\left(\frac{\left(a-2 c_{2}+c_{1}+\varepsilon-r\right)^{2}}{9}-\frac{\left(a-2 c_{2}+c_{1}-\varepsilon+r\right)^{2}}{9}\right)+ \\
& r\left(\frac{\left(a-2 c_{1}+\varepsilon-r+c_{2}\right)}{3}+\frac{\left(a-2 c_{2}+c_{1}+\varepsilon-r\right)}{3}\right)
\end{aligned}
$$

Maximising the above payoff with respect to $r$ we get

$$
r^{*}=\frac{\left(6 \varepsilon-2 a-11 c_{1}+13 c_{2}\right)}{12} \text {. }
$$

Note that the natural restriction is $0 \leq r^{*} \leq \varepsilon$.

Now for $2 a \geq 13 c_{2}-11 c_{1}+6 \varepsilon, r^{*} \leq 0$; this means the optimal $r^{*}=0$. 
For $2 a \leq 13 c_{2}-11 c_{1}-6 \varepsilon, r^{*} \geq \varepsilon$; so the optimal $r^{*}=\varepsilon$.

Thus, the two part tariff is optimal when the following condition holds

$13 c_{2}-11 c_{1}+6 \varepsilon>2 a>13 c_{2}-11 c_{1}-6 \varepsilon$

The optimal value of $f^{*}$ is obtained from (A4) plugging the value of $r^{*}<\varepsilon$ from (A6).

First consider the two extreme cases of only royalty and only fixed fee regime. When $2 a \geq 13 c_{2}-11 c_{1}+6 \varepsilon$ then optimal $r^{*}=0$ from (A6) and only fixed fee is charged to both firms and hence the patentee's payoff is

$$
\mathrm{L}^{2}(f)=2\left[\frac{4}{9} \varepsilon\left(a-2 c_{2}+c_{1}\right)\right]
$$

On the other extreme when $13 c_{2}-11 c_{1}-6 \varepsilon \leq 2 a$ then the patentee charges a uniform royalty $r^{*}=\varepsilon$ to both firms and thus the total payoff to the patentee would be (from (A5))

$$
\mathrm{L}^{2}(r)=\varepsilon\left[\frac{a-2 c_{1}+c_{2}}{3}+\frac{a-2 c_{2}+c_{1}}{3}\right]=\varepsilon\left[\frac{2 a-c_{1}-c_{2}}{3}\right]
$$

However, for the intermediate range of parameters given by the condition (A7), $13 c_{2}-11 c_{1}+6 \varepsilon>2 a>13 c_{2}-11 c_{1}-6 \varepsilon$, the optimal licensing is a two part tariff and plugging the value of $r^{*}$ and $f^{*}$ (from (A6) and (A4)) into (A5) we get the patentee's payoff after simplification

$L^{2}\left(f^{*}, r^{*}\right)=\frac{4 a^{2}+121 c_{1}^{2}+169 c_{2}^{2}+36 \varepsilon^{2}+168 a \varepsilon+44 a c_{1}-52 a c_{2}+60 \varepsilon c_{1}-228 \varepsilon c_{2}-286 c_{1} c_{2}}{216}$

\section{Proof of Proposition 1}

Note that the optimal payoff for the patentee under patent licensing is given under one license by (7) and under two licenses as $L^{2}(f), L^{2}(r)$ and uniform two part tariff $L^{2}\left(f^{*}, r^{*}\right)$ in ((A8), (A9) and (A10)). Now we compare them with the option of patent right sale given in (3) as $R_{1}=\varepsilon\left(a-c_{1}\right)$. Recall our Assumption 1, which is useful to determine some of the signs of the expression below. From (7) and (3) 


$$
R_{1}-L^{1}(f)=\varepsilon\left(a-c^{1}\right)-\operatorname{Max} \cdot\left\{\frac{1}{3} \varepsilon\left(2 a-4 c_{2}+2 c_{1}+\varepsilon\right), \frac{4 \varepsilon\left(a-2 c_{1}+c_{2}+\varepsilon\right)}{9}\right\}
$$

Comparing with the first term of the Max. expression we get

$$
\varepsilon\left(a-c_{1}\right)-\frac{1}{3} \varepsilon\left(2 a+\varepsilon+2 c_{1}-4 c_{2}\right)=\frac{1}{3} \varepsilon\left(a-\varepsilon-5 c_{1}+4 c_{2}\right)>0
$$

Comparing with the second term we get

$$
\varepsilon\left(a-c_{1}\right)-\frac{4 \varepsilon\left(\mathrm{a}-2 c_{1}+c_{2}+\varepsilon\right)}{9}=\frac{1}{9} \varepsilon\left(5 a-c_{1}-4 c_{2}-4 \varepsilon\right)>0
$$

By comparing $R_{1}$ directly with $L^{2}(r)$ we find

$$
\begin{gathered}
R^{1}-L^{2}(r)=\varepsilon\left(a-c_{1}\right)-\frac{1}{3} \varepsilon\left(2 a-c_{1}-2 c_{2}\right) \\
=\frac{1}{3} \varepsilon\left(a-2 c_{1}+c_{2}\right)>0 \\
R_{1}-L^{2}(f)=\varepsilon\left(a-c_{1}\right)-\frac{8}{9} \varepsilon\left(a+c_{1}-2 c_{2}\right)=\frac{1}{9} \varepsilon\left(a-17 c_{1}+16 c_{2}\right)>0
\end{gathered}
$$

The only remaining patent licensing to compare is between the two part tariff licensing $L^{2}\left(f^{*}, r^{*}\right)$ and the option of patent sale. Recall that the two part tariff is optimal only under condition (A7). Now by comparing (A10) and (3) we find that the patent sale is strictly better than the two part tariff licensing to both firms provided that

$$
72 \varepsilon\left(a-2 c_{1}+c_{2}\right)>\left(2 a-13 c_{2}+11 c_{1}+6 \varepsilon\right)^{2} .
$$

To check that the condition always holds under the parameter restrictions given by (A7), we proceed as follows. The LHS is an increasing function and the RHS is a decreasing function of $c_{2}$. Thus the LHS attains the minimum and the RHS attains the maximum when $c_{2}$ tends to the lower limit $c_{1}$. Thus, plugging the value $c_{2}=c_{1}$, the condition (A11) becomes

$$
72 \varepsilon\left(a-c_{1}\right)>4\left(a-c_{1}+3 \varepsilon\right)^{2}
$$

This imples

$18 \varepsilon\left(a-c_{1}\right)>\left(a-c_{1}+3 \varepsilon\right)^{2}$

Now with $c_{2}=c_{1}$, the condition (A7) becomes $c_{1}+3 \varepsilon>a>c_{1}-3 \varepsilon$. Along with Assumption 1 we have $\varepsilon<a-c_{1}<3 \varepsilon$. Now in (A11') the rise in LHS is sharper than the rise in RHS with respect to $\left(a-c_{1}\right)$, since $18 \varepsilon>2\left(a-c_{1}+3 \varepsilon\right)$ for $\varepsilon<a-c_{1}<3 \varepsilon$. Thus the LHS attains minimum at $a-c_{1}=\varepsilon$ and still the inequality (A11') holds.

Thus, the payoffs to the outside patentee is always higher under the patent sale than the payoffs from patent licensing directly to the firms. 


\section{Proof of Lemma 5}

Suppose firm i buys the technology and as a result its cost of production is $\mathrm{c}$ and its rival $j$ 's cost is $c_{j}$. Consider the general licensing scheme (f, $r$ ), where $f \geq 0, r \geq 0$. After accepting the licensing contract, firm j's cost of production would be $c+r$. Thus, the profits of firm $i$ and $j$ under Cournot competition in the third stage of the game would be

$$
\pi_{i}=\frac{(a-c+r)^{2}}{9} \text { and } \pi_{j}=\frac{(a-c-2 r)^{2}}{9}
$$

If the licensing contract is either not offered or it is rejected then the profits in the third stage of the game would be

$$
\pi^{N l}{ }_{i}=\frac{\left(a-2 c+c_{j}\right)^{2}}{9} \text { and } \pi^{N L}{ }_{j}=\frac{\left(a-2 c_{j}+c\right)^{2}}{9}
$$

Firm $i$ offers the licensing contract to firm $j$ such that firm $j$ 's participation constraint is satisfied and also firm i receives greater payoff than not offering the license. Note that the maximal fixed fee the firm i can charge under $(f, r)$ contract is

$\mathrm{f}=\frac{(a-c-2 r)^{2}}{9}-\frac{\left(a-2 c_{j}+c\right)^{2}}{9}$.

Thus firm i's payoff from licensing and subsequent competition would be

$$
\pi_{i}=\frac{(a-c+r)^{2}}{9}+\frac{(a-c-2 r)^{2}}{9}-\frac{\left(a-2 c_{j}+c\right)^{2}}{9}+r \frac{(a-c-2 r)}{3}
$$

To maximize the above payoff subject to the constraint that the fixed fee is non-negative we have to ensure $r \leq c_{j}-c$. It is easy to see that the payoff of the patent buyer would be increasing in $\mathrm{r}$ for $r \leq c_{j}-c$. Hence the optimal licensing contract is only royalty $r^{*}=c_{j}-c$ and no fixed fee $f=0$. With this licensing contract the optimal payoff to the patent buyer i would be

$$
\pi^{*}{ }_{i}=\frac{\left(a-2 c+c_{j}\right)^{2}}{9}+\left(c_{j}-c\right) \frac{\left(a-2 c_{j}+c\right)}{3} \text {. }
$$

\section{Proof of Lemma 7}

When two licenses are offered, the outside patentee would have to offer the same contract $(f, r)$ to both firms such that the participation constraint of the efficient firm is satisfied. As a result the 
participation constraint of the inefficient firm would be automatically satisfied. For a given $r$ the amount of fixed fee the efficient firm would be willing to pay is given by

$\frac{(a-c-r)^{2}}{9}-\frac{\left(a-2 c_{1}+c+r\right)^{2}}{9}$.

By accepting the same menu the inefficient firm receives a greater payoff than what it gets by rejection ( since $\mathrm{c}_{1}<\mathrm{c}_{2}$ ).

Hence, by plugging the values of $(f, r)$ collected from both firms the outside patentee receives

$$
2\left(\frac{(a-c-r)^{2}}{9}-\frac{\left(a-2 c_{1}+c+r\right)^{2}}{9}\right)+2 r\left(\frac{a-c-r}{3}\right) .
$$

The unconstrained maximization of the above expression yields

$$
r * \frac{4 c_{1}-3 c-a}{6}
$$

However, the optimal royalty has to satisfy $0 \leq r^{*} \leq \delta_{1}=c_{1}-c$. Note that $r^{*} \leq \delta_{1}$ is naturally satisfied since $a>c_{1}>c$. Hence, we characterize the choice of optimal $\mathrm{r}^{*}$ as follows :

$r *=0$ if $c<c_{1}<\frac{a+3 c}{4}$

$r *=\frac{4 c_{1}-3 c-a}{6}$ if $\frac{a+3 c}{4}<c_{1}<\frac{a+c}{2}$.

When $r *=0$, then only fixed fee is charged to both firms and in the other case both royaly and fixed fee are charged.

Now we are in a position to write down the total payoff the outside patentee will receive when it offers two licenses. Plugging the values of relevant $r^{*}$ and $f^{*}$ in equation (A15) we get the patentee's payoff as follows.

$\mathrm{N}^{2}(\mathrm{f})=\frac{(a-c)^{2}}{9}-\frac{\left(a-2 c_{1}+c\right)^{2}}{9}=\frac{8}{9}\left(a-c_{1}\right)\left(c_{1}-c\right)$, for $c<c_{1}<\frac{a+3 c}{4}$;

$\mathrm{N}^{2}(\mathrm{f}, \mathrm{r})=\frac{(a-c-r *)^{2}}{9}-\frac{\left(a-2 c_{1}+c+r *\right)^{2}}{9}+2 r *\left(\frac{(a-c-r *)}{3}\right)$ for $\frac{a+3 c}{4}<c_{1}<\frac{a+c}{2}$.

Where $r *$ is given by (A16) above.

\section{Proof of Proposition 2.}

We compare the payoff difference between the patent sale and the direct licensing to one firm. First by comparing with the first term in (10) we find that the patent sale is better iff 
$\frac{\left(a-2 c+c_{2}\right)^{2}}{9}+\left(c_{2}-c\right) \frac{\left(a-2 c_{2}+c\right)}{3}-\frac{\left(a-2 c_{1}+c\right)^{2}}{9}-\frac{\left(a-2 c+c_{2}\right)^{2}}{9}+\frac{\left(a-2 c_{1}+c\right)^{2}}{9}$ $=\left(c_{2}-c\right)\left(\frac{1}{3} a+\frac{1}{3} c-\frac{2}{3} c_{2}\right)>0,\left(\right.$ since Assumption 2 holds and $\left.c_{2}-c>0\right)$.

Now comparing with the second term in (10) we find that

$$
\begin{aligned}
\frac{\left(a-2 c+c_{2}\right)^{2}}{9} & +\left(c_{2}-c\right) \frac{\left(a-2 c_{2}+c\right)}{3}-\frac{\left(a-2 c_{1}+c\right)^{2}}{9}-\frac{\left(a-2 c+c_{1}\right)^{2}}{9}+\frac{\left(a-2 c_{2}+c\right)^{2}}{9} \\
& =\frac{1}{9} a c_{2}+\frac{2}{9} a c_{1}+\frac{8}{9} c c_{1}+\frac{1}{9} c c_{2}-\frac{1}{3} c^{2}-\frac{1}{3} a c-\frac{5}{9} c_{1}{ }^{2}-\frac{1}{9} c_{2}{ }^{2}
\end{aligned}
$$

This is an increasing function of $c_{2}$ and the minimum is attained when $c_{2}=c_{1}$. Thus, the above expression becomes $3\left(\mathrm{c}_{1}-\mathrm{c}\right)\left(\mathrm{a}+\mathrm{c}-2 \mathrm{c}_{1}\right)>0$, by Assumption 2 .

Finally, we find that $T_{2}>N^{1}(F)$ by simple observation of their respective expressions and we have already seen that $T_{1}>T_{2}$ (by lemma 6 ).

Comparing (8) and (A17), we find that $\mathrm{T}_{1}$ is strictly better than $N^{2}(f)$ for $c<c_{1}<\frac{a+3 c}{4}$ if $5 a c_{2}-$ $4 a c_{1}-a c+4 c c_{1}+5 c c_{2}+4 c_{1}{ }^{2}-5 c_{2}{ }^{2}>0$. Note that this is a strictly negative function of $c_{1}$ and the upper limit of $c_{1}$ is $c_{2}$. At the upper limit the above expression becomes $\frac{1}{9}\left(a-c_{2}\right)\left(c_{2}-c\right)$, which is greater than zero. On the other hand at the lower limit of $c_{1}$, i.e., c, the value is $\frac{5}{9}\left(a-c_{2}\right)\left(c_{2}-c\right)$, which is also positive. This proves that patent sale to the efficient firm is strictly better than the fixed fee licensing for $c<c_{1}<\frac{a+3 c}{4}$.

Now consider the other parameter range $\frac{a+3 c}{4}<c_{1}<\frac{a+c}{2}$. For this parameter configurations, from (8) and (A18) we find that $\mathrm{T}_{1}$ is strictly better than $N^{2}(f, r)$ provided 30ac $2-16 a c_{1}-12 a c-$ $a^{2}+4 c c_{1}+30 c c_{2}-9 c^{2}+8 c_{1}{ }^{2}-30 c_{2}{ }^{2}$ is positive. Define $c_{2}=c_{1}+x$, where $\mathrm{x}$ is a positive number that belongs to $\left(0, \frac{(a-c)}{4}\right)$. Plugging the value of $c_{1}$ in terms of $x$, we get the expression as $14 a c_{2}+16 a x-12 a c-a^{2}+4 c c_{1}+30 c c_{2}-9 c^{2}+8 x^{2}-16 x c_{2}-22 c_{2}{ }^{2}$. This is a strictly positive function of $x$. Thus the minimum value is attained at $x=0$. At $x=0$ The expression becomes $14 a c_{2}-12 a c-a^{2}+4 c c_{1}+30 c c_{2}-9 c^{2}-22 c_{2}{ }^{2}$, which is a strictly concave function of $c_{2}$ and the expression is maximized at $c_{2}=\frac{7 a+15 c}{22}$. This belongs to the parameter range as $\frac{a+3 c}{4}<$ 
$\frac{7 a+15 c}{22}<\frac{a+c}{2}$ holds. Given the concavity of the function with respect to $c_{2}$, now evaluate the function at the two extreme values. At the upper limit of $c_{2}$ i.e. at $\frac{a+c}{2}$ the difference in payoffs becomes $\frac{(a-c)^{2}}{2}$, which is greater than zero. At the lower limit of of $c_{2}$ i.e. at $\frac{a+3 c}{4}$ the difference in payoffs becomes $\frac{9(a-c)^{2}}{8}$, which is greater than zero. Since the payoff difference is an increasing function of $x$, the payoff difference is always positive. Note that when x goes to the upper limit at $\frac{(a-c)}{4}$, the value of $c_{2}$ must be $\frac{a+3 c}{4}$. Then the payoff difference becomes $3(a-c)^{2}$. Thus, for all possible parameter constellations admissible in the given context we have that $\mathrm{T}_{1}$ is strictly better than $N^{2}(f, r)$.

Hence, the Proposition 2 is proved. 


\section{References}

Bousquet, A., Cremer, H., Ivaldi, M. and Wolkowicz, M. (1998), 'Risk Sharing in Licensing', International Journal of industrial Organization, 16, 535-554.

Fauli-Oller, R. and Sandonis, J. (2002), 'Welfare Reducing Licensing', Games and Economic Behavior, 41, 192-205.

Gallini, N. and Wright, B. D. (1990), 'Technology Transfer under Asymmetric Information', Rand Journal of Economics, 21, 147-160.

Kamien, M. (1992), 'Patent Licensing', In Aumann, R. J., and Hart, S. (Eds.), Handbook of Game Theory with Economic Applications, Elsevier Science, North Holland, 331-354 .

Kamien, M. I., Oren, S. S. and Tauman, Y. (1992), 'Optimal licensing of cost reducing Innovation', Journal of Mathematical Economics, 21, 483-508.

Kamien, M. I. and Tauman, Y. (1986), 'Fees versus Royalties and the Private Value of a Patent', Quarterly Journal of Economics, 101, 471-491.

Kamien, M. I. and Tauman, Y. (2002), 'Patent Licensing: the Inside Story', The Manchester School, 70, 7-15.

Katz, M. and Shapiro, C. (1985), 'On the Licensing of Innovations', RAND Journal of Economics, 16, 504-520.

Lu, Y. and Poddar, S., (2014), 'Patent Licensing in Spatial Models', Economic Modelling, 42, 250 256.

Macho-Stadler, I., Martinez, X., Prerez-Castrillo, D. (1991), Contracts de License et Asymetrie d'Information. Annales d'Economie et de Statistique, 24, 189-208.

Mukherjee, A. (2007), 'Optimal Licensing Contract in an Open Economy', Economics Bulletin, 12, 1-6.

Poddar S. and Sinha, U. B. (2008), 'On Patent Licensing', in Roberto Cellini and Luca Lambertini (eds.), The Economics of Innovation: Incentives, Cooperation, and R\&D Policy, Emerald UK, 3365.

Poddar S. and Sinha, U. B. (2010), Patent Licensing from High-Cost Firm to Low-Cost Firm, The Economic Record, Vol. 86. Issue 274, 384-395.

Saracho, A. I. (2002), 'Patent Licensing under Strategic Delegation', Journal of Economics and Management Strategy, Volume 11, Number 2, 2002, 225-251. 
Sen, D., Tauman, Y. (2007), 'General Licensing Schemes for a Cost-Reducing Innovation', Games and Economic Behavior, 59, 163-186.

Stamatopolous G. and Tauman, T. (2009), On the superiority of fixed fee over auction in asymmetric markets, Games and Economic Behavior, 67, 331-33.

Tauman, T. and Weng , M-H. (2012), "Selling Patent Rights and the Incentive to Innovate", Economics Letters, 114, 241-244.

Tirole, J. (1988), The Theory of Industrial Organization, The MIT Press, Cambridge, Massachusetts.

Wang, X. H. (1998), 'Fee versus Royalty Licensing in a Cournot Duopoly Model', Economics Letters, 60, 55-62.

Wang, X. H. and Yang B. (2004), 'On Technology Transfer to an Asymmetric Cournot Duopoly', Economics Bulletin, Vol. 4, No. 14 pp. 1-6. 